\title{
The caspase-dependent apoptosis gradient in the testis of the blue shark, Prionace glauca
}

\author{
Leon M McClusky \\ Faculty of Health and Society, Narvik University College, Narvik, Norway \\ Correspondence should be addressed to L M McClusky; Email: leonmc@hin.no
}

\begin{abstract}
The severe degenerative phenomena that characterises spermatogenesis in mating blue sharks involves spatially separated germ cell and Sertoli cell apoptosis. Unlike that observed in multilayered type B spermatogonial and spermatocyte cysts caspase-3-dependent apoptosis of single and multinucleate type B spermatogonia in one to three spermatogonial layered cysts resulted in their complete fragmentation, delayed phagocytic removal and displacement of the apoptotic bodies towards the perilumenar Sertoli nuclei. Changes were observed in the immunostaining patterns of proliferating cell nuclear antigen (PCNA), including subtle changes in cytoplasmic and overall intense immunostaining, labelled single and multinucleate cell (MNC) apoptotic spermatogonial masses in premeiotic cysts in different stages of the protracted death process. Initial massive MNC formation at the mitosis-meiosis transition eventually left its imprint in the spermatogenic sequence in the form of vacuolated areas in the affected and subsequent stages. Some of the latter attempted further developmental advance but eventually degenerated. The observed higher PCNA index of spermatogonia in vacuolated testes compared to testes with the MNC type of degeneration indicated that the former testicular morphology represented, in essence, the recovery phase from the pronounced MNC death earlier. Events culminating in the eventual apoptotic demise of the Sertoli cells themselves included the abortion of further development (presumably due to a suboptimal Sertoli:germ cell ratio) of those germ cells left over from the wave of MNC death that swept the cysts. Eventually the Sertoli-cell-only cysts became apoptotic as they were engulfed by the infiltrating lymphomyeloid cells from the epigonal organ associated with the mature pole of the testis.
\end{abstract}

Reproduction (2013) 145 297-310

\section{Introduction}

Not all germ cells complete the process of spermatogenesis, i.e. the development of a committed spermatogonium stem cell into a highly differentiated spermatozoan. These damaged, superfluous or inadequately supported germ cells are phagocytised by Sertoli cells, which have an overall responsibility to maintain the structural integrity of the spermatogenic epithelium. Given the presence of intercellular bridges (Dym \& Fawcett 1971, Pudney 1995) between all germ cells that stem from a common spermatogonial progenitor it is therefore remarkable that spontaneous germ cell deletion, as a general rule, manifests as a scattering of single, isolated dying germ cells and, very rarely, as long chains of degenerating germ cell clones in the spermatogenic epithelium. This condition has, in rodents at least, often been ascribed to the rapid and efficient phagocytic activity of the closely positioned Sertoli cells (Russell \& Clermont 1977, Bartke 1995, Billig et al. 1995). All of this is in stark contrast to that seen in lower vertebrates where entire germinal clones enter apoptosis (Yazawa et al. 2003, Corriero et al. 2007, McClusky et al. 2008).

An unusual aspect though of testicular cell death in some lower vertebrates, such as sharks, is its spatially graded pattern of individual and multinucleate cell (MNC) deaths in successive spermatogonial clones. Thus there is the formation of a degenerate zone comprising several layers of apoptotic multilayered spermatogonial clones that is tolerated for several months in the testis (McClusky 2005, 2006). By all accounts, such a highly degenerative state, which is also seen in another dogfish, Scyliorhinus canicula (Dobson \& Dodd 1977), seems not, contrary to accepted dogma (Kroemer et al. 2008), to resemble a 'clean' and orderly form testicular death and is suggestive of a delayed and protracted elimination process even as other clones develop normally.

Evidence from studies on mice point to a link between no or delayed phagocytic removal of dead germ cells by Sertoli cells and exaggerated death phenomena other than classic apoptosis in a scattering of cells. For example, the absence of the engulfment and cell motility protein 1 (ELMO1) cytoplasmic engulfment protein in germ cells is associated with massive MNC death and reduced clearance of apoptotic cells (Elliott et al. 2010) and the observed disintegration of dead germ cells with necrotic-like features at the testicular age when only immature Sertoli cells are found in mice 
(Wang et al. 1998). The notion of a link between the extent to which doomed MNCs are tolerated in the testis and the functional age/status of the Sertoli cells is further supported by findings of the frequent incidence of MNC formation in the immature (Morton et al. 1986) and aged mammalian testis (Paniagua et al. 1987, Miething 1993). What is not known is the extent to which the morphology of germ cell death and clearance of the cell corpses might, if at all, be determined by the stage of the Sertoli cell's own development. The vertebrate Sertoli cell also experiences a bout of mitosis in the immature animal before it enters a postmitotic state as puberty approaches. Unlike in mammals however Sertoli cells in lower vertebrates are not permanent elements of the spermatogenic epithelium. New Sertoli cells proliferate and mature together with germ cells during each spermatogenic cycle (McClusky 2005, Schulz et al. 2005).

The study of spermatogenesis in lower vertebrates is therefore useful for exploring, among other phenomena changes within the germinal clones and their stagesynchronised Sertoli cells that might about the sequence of the unusually protracted death and elimination process. The germinal clones of the shark testis are anatomically distinct spherical follicle-like units called spermatocysts. Each cyst also houses a second clonal population of stagesynchronised Sertoli cells. The cysts are arranged in a maturational order across the diameter of the testis providing a readily visible zonation of the testis comprising cysts in the premeiotic (PrM, spermatogonia and preleptotene spermatocytes), meiotic (spermatocytes) and postmeiotic (PoM, spermatids) regions.

We previously reported that, unlike in the type of testicular degeneration seen in the diametric testes of other carcharhinid sharks (Dobson \& Dodd 1977, McClusky 2005), the diametric blue shark testis shows massive spermatocyst degeneration of not only the PrM cysts containing the latter generations of type B spermatogonia but also meiotic and PoM cysts in summer mating individuals caught in the western North Atlantic (McClusky 2011). The degenerative phenomena were by comparison more extensive than that seen in other sharks with a similar testis type with two types of degeneration noted, i.e. MNC formation and vacuolated appearance. The aim of this study was to elucidate the mechanism of testicular degeneration in the blue shark, the sequence of events that characterise the extensive cyst degeneration seen in the PoM region of the testis and how these phenomena relate to the lymphomyeloid tissue mass (epigonal organ) that is uniquely associated with the mature pole of the elasmobranch testis.

\section{Results}

Given the previous findings of massive spermatocyst degeneration that particularly affected the spermatogonia-spermatocyst transition (McClusky 2011) investigations initially centred on elucidating the mechanism of cyst degeneration in this region of the testis. Probing the sections with classic immunohistochemical markers of apoptosis, e.g. the TUNEL method, generally result in strong, intense and sometimes overwhelming labelling of the whole cell or groups of cells that are engaged in the apoptotic death process and that may obscure more subtler intracellular changes (McClusky 2005). As a cell's survival versus death decisions are made while it is still engaged in the cell cycle, it was therefore decided to focus the immunohistochemical investigations on comparing the immunostaining patterns of the apoptosis markers in normallooking, proliferatively active cysts, with that of the conserved cell cycle marker (proliferating cell nuclear antigen (PCNA)) in cysts containing many apoptotic cells.

Analysis of TUNEL and cleaved caspase-3 immunostaining patterns in normal-looking late-stage PrM cysts housing proliferatively active type B spermatogonia showed occasional TUNEL- (Fig. 1A) and

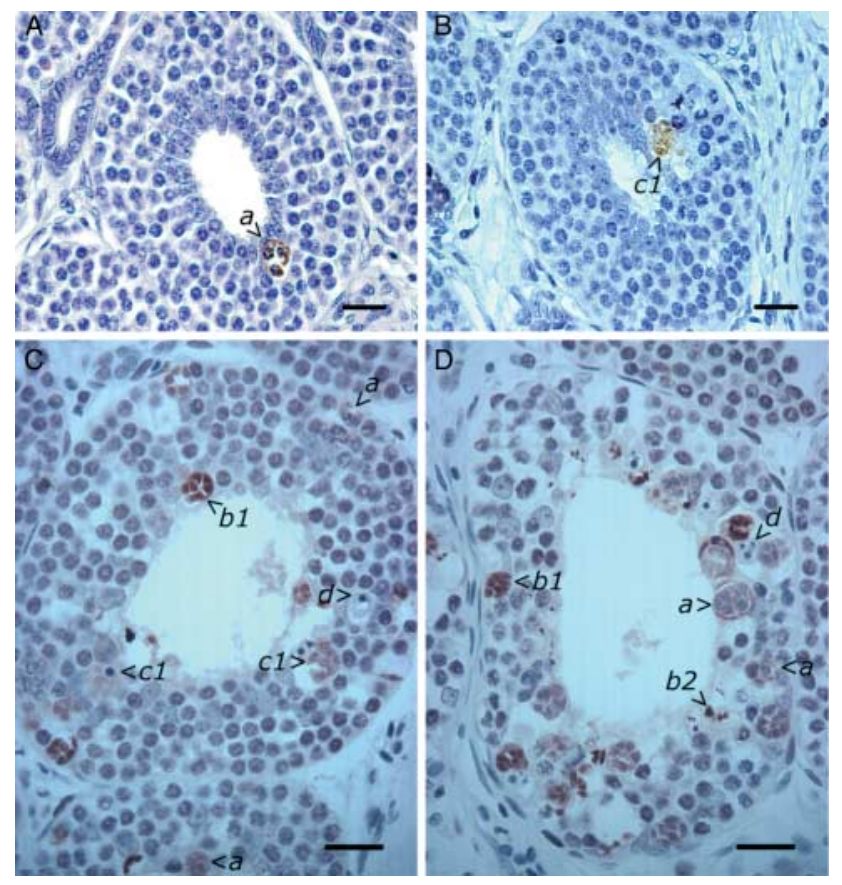

Figure 1 Comparative (A) TUNEL, (B) cleaved caspase- 3 and (C and D) PCNA immunostaining patterns of multilayered PrM cysts exhibiting varying degrees of degeneration in $P$. glauca testicular cross-sections. Normal-looking M-PrM cysts may occasionally show cytoplasmic TUNEL (A) and caspase-3 (B) labelling of multinucleate spermatogonial masses whose nuclei may $(A$, a) or may not always $(B, C 1)$ be distinguishable. PCNA immunohistochemistry of apoptotic PrM cysts (C and D) also facilitates the identification of various phases of the apoptotic death process, namely moderate cytoplasmic (a) and overall intense (b1) immunostaining of single spermatogonia, multinucleate spermatogonial masses and cellular fragments dislodging from multinucleate spermatogonial masses (b2); moderately labelled giant coalesced masses and their associated condensed chromatin clumps (c1) or PCNA-negative coalesced shrinking masses and their associated clumps of condensed chromatin (d). Scale bars: $\mathrm{A}$ and $\mathrm{B}=20 \mu \mathrm{m} ; \mathrm{C}$ and $\mathrm{D}=50 \mu \mathrm{m}$. 

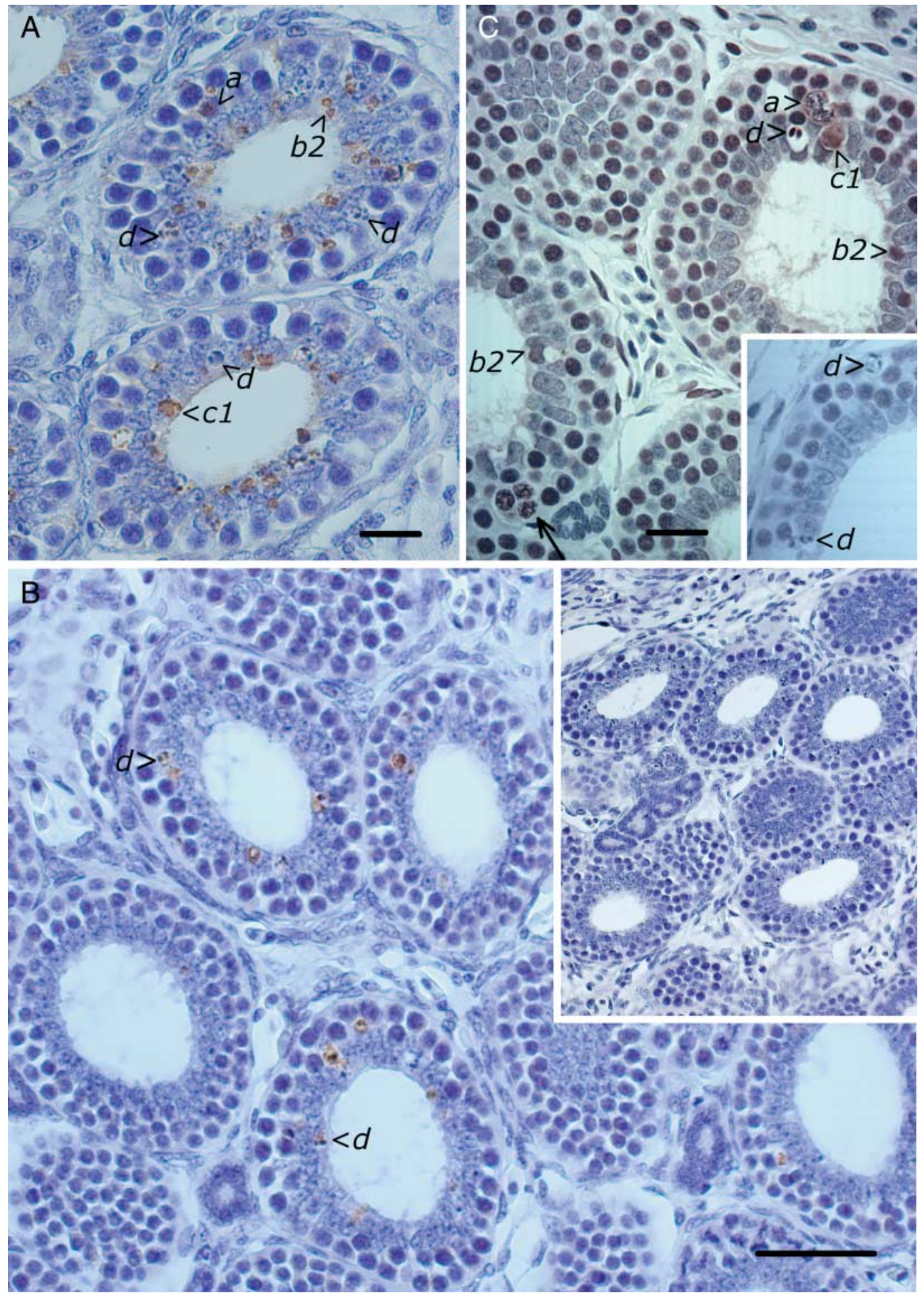

Figure 2 Comparative (A) TUNEL, (B) cleaved caspase-3 and (C) PCNA immunostaining patterns of E-PrM cysts in P. glauca testicular cross-sections. TUNEL (B) and cleaved caspase-3 (C) immunolabelled apoptotic bodies were found mostly amongst the Sertoli nuclei (a, b2 and c1). Apart from the homogeneous nuclear immunostaining of cycling spermatogonia, the PCNA antibody also (C) distinctly labels the cytoplasm of single or coalesced spermatogonia with a peculiar chromatin arrangement (a), which is an early indication of multinucleate cell formation (arrow). PCNA distinctly labels the corresponding TUNEL-labelled fused cellular masses (c1) and apoptotic bodies (b2). Single apoptotic spermatogonia may also complete the death process on the cyst periphery as shown by the condensed, marginated chromatin (d), which is neither PCNA (inset A) nor TUNEL labelled (B), but caspase-3 immunolabelled (B). (Inset B) Shows negative control with the cleaved caspase-3 antibody. Scale bars: A and B = 20 $\mu \mathrm{m} ; \mathrm{C}=50 \mu \mathrm{m}$. 
caspase-3-positive (Fig. 1B) cytoplasmic labelling that delineated a cluster of spermatogonia with (Fig. 1A) or without distinguishable nuclei (Fig. 1B). In contrast PCNA immunostaining in the same PrM cysts with many dying spermatogonia showed not only the moderate nuclear PCNA immunostaining associated with cycling spermatogonia (Fig. 1C) but also distinct, cytoplasmic labelling of single spermatogonia and large multinucleate spermatogonial masses (Fig. 1D), as well as complete intense immunolabelling of large multinucleate spermatogonial masses (Fig. 1C and D). Further development was marked by reduced PCNA immunostaining associated with the complete coalescence of the affected spermatogonia and in those whose nuclei were not discernible (Fig. 1C and D). Instead one to three condensed chromatin masses were found in these fused cellular masses.

These findings prompted an immunohistochemical analysis of the early (E)-PrM cysts, i.e. spermatogonial generations just upstream from mid-stage (M)-PrM cysts and where cell cycle balance in the cysts is known to be tilted towards mitotic activity due to cycling type B spermatogonia at a time when Sertoli cell proliferation is also known to approach its conclusion in other elasmobranchs. Also these cyst stages are known to be relatively resistant to apoptosis in other sharks with the diametric testis type.

TUNEL staining (Fig. 2A), more so than cleaved caspase-3 immunostaining (Fig. 2B), revealed extensive labelling of round structures of various sizes found just above the innermost spermatogonial layer but predominantly amongst the Sertoli nuclei located around the cyst lumen. Those round structures with condensed, marginated chromatin were TUNEL-negative (Fig. 2A, d) but caspase-3-positive (Fig. 2B, d), and were also the only structures that were immunodetected by cleaved caspase-3 immunohistochemistry. In contrast variations in the quality of PCNA immunostaining of cell death and related phenomena were associated with the overall intensity of the nuclear PCNA immunostaining of normal cycling spermatogonia. When the latter was strong the overall incidence of distinct PCNA immunolabelling of cell death and related phenomena (individual and clusters of coalesced spermatogonia, their corpses and cell debris) was low (Fig. 2C). Nevertheless, the latter phenomena were often found in the innermost spermatogonial layer, or interspersed amongst the Sertoli nuclei bordering the cyst lumen (Fig. 2C). Only rarely was spermatogonial cell death with its distinctive apoptotic morphology, which was always PCNA negative, completed near the basement membrane (Fig. 2C). Comparative quantitative analysis of the incidence of condensed chromatin-containing apoptotic bodies in E-PrM 1 and E-PrM 2 cysts in the two degenerative conditions showed no significant differences although the overall incidence tended to be lower in E-PrM 2 cysts (Fig. 3).

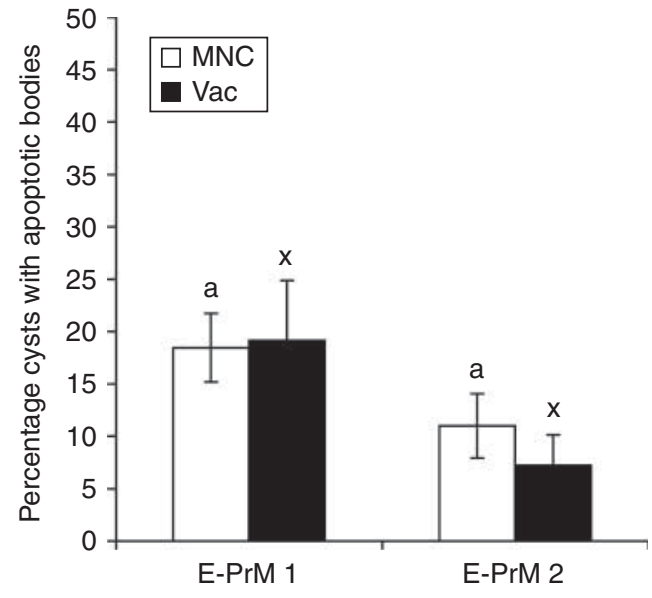

Figure 3 Occurrence of apoptotic bodies in E-PrM cysts in the two main categories of testicular degeneration seen in Prionace glauca. Values represent the mean percentage of E-PrM cysts containing three or more apoptotic bodies \pm s.E.M. analyzed by one-way ANOVA. The Student-Newman-Keuls multiple comparisons test was used to identify means that differed significantly. Different letters indicate significant differences in the MNC ( $a$ and $b$ ) and vacuolated ( $x$ and $y$ ) types of testicular degeneration.

Immunohistochemical analysis of newly formed cysts, i.e. the germinal zone (GZ) cysts that are known to experience both intense spermatogonial and Sertoli cell proliferation, revealed none of the above apoptosis or related death phenomena (Fig. $4 \mathrm{~A}$ and B). PCNA immunohistochemistry often revealed evidence of alternating cyst cell cycle activity of either only Sertoli cells (Fig. 4C) or only spermatogonia (Fig. 4D) in clusters of GZ cysts separated by stroma of trabeculae originating in the germinal ridge.

The wave of apoptotic MNC formation that initiated in the M-PrM and L-PrM cysts also affected spermatocyte cysts, if these were present at the time (Fig. 5A). As apoptosis did not affect all germ cells in a cyst such cysts recovered giving rise to subnormally sized, severely germ cell-depleted spermatocyte cysts (Fig. 5B). In animals where the spermatogonia-spermatocyte transition appeared to be normal, the large meiotic cysts were neither Tunel- (Fig. 5C) nor cleaved caspase-3 (Fig. 5D) immunolabelled, which was characteristic of the vacuolated type of degeneration that also featured the displacement of the zone of degeneration well towards the mature pole of the testis. In other testicular conditions, e.g. towards the end of the period of MNC formation, the presence of numerous subnormal-sized severely depleted spermatocyte and spermatid cysts (Fig. 5E and F) was associated with an influx of epigonal-derived lymphomyeloid cell islands to the meiotic region. The latter cyst morphologies showed qualitatively different TUNEL- (Fig. 5E) and caspase-3positive (Fig. 5F) labelling, i.e. only the last remaining germ cell corpses in the Sertoli cytoplasm were Tunelpositive (Fig. 5E). In contrast with caspase-3 

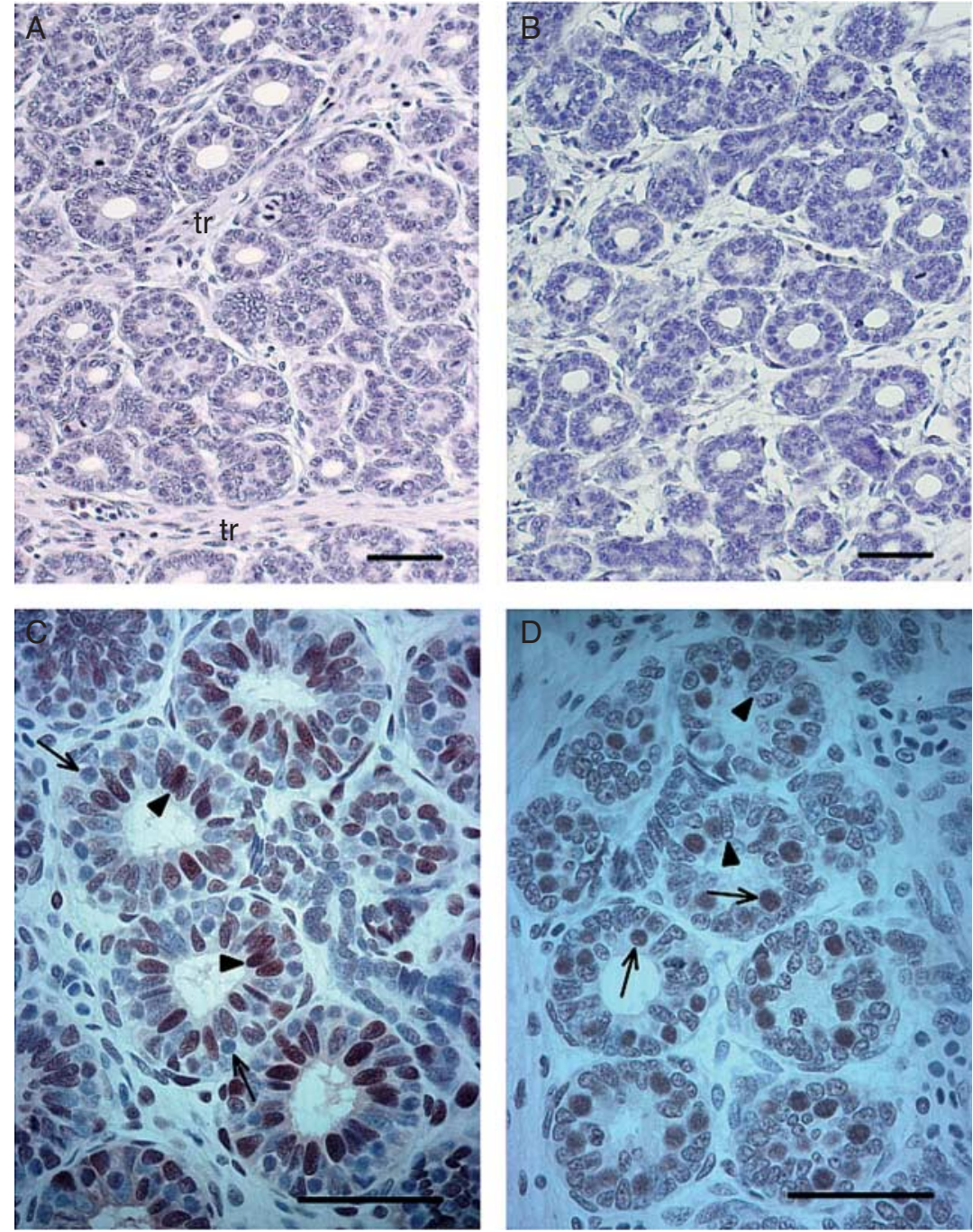

Figure 4 Comparative (A) TUNEL, (B) cleaved caspase-3 and (C and D) PCNA immunostaining patterns of GZ cysts in P. glauca testicular crosssections. No apoptotic cells are immunolabelled with either TUNEL (A) or caspase-3 (B) immunohistochemistry. PCNA immunohistochemistry often reveals alternating PCNA-positive labelling of either only Sertoli cells (C, arrowhead) or only spermatogonia ( $D$, arrow) in clusters of $G Z$ cysts separated by stroma of trabeculae (tr) originating in the germinal ridge. Scale bar $=50 \mu \mathrm{m}$. immunostaining the cytoplasm of the majority of normal-looking germ cells in these spermatocyte cysts were caspase-3-immunostained while the Sertoli cytoplasm itself was not caspase-3 labelled (Fig. 5F).

All PCNA immunohistochemical findings were quantified according to cyst stage to determine how the expansion of germinal and Sertoli cell clones in the PrM and meiotic regions might be affected by the two degenerative conditions (Fig. 6). Changes in the percentage of PCNA-immunoreactive GZ and E-PrM cysts were stage-dependent and cell-type-specific. Although overall differences among GZ cysts were statistically significant $(P=0.0113)$, cell-type-specific differences in PCNA immunostaining as well as differences between the two types of degeneration were not significant (Fig. 6A). Overall differences in PCNA immunostaining among E-PrM 1 cysts (Fig. 6B) were significant $(P<0.0001)$. In the vacuolated type of degeneration, the proportion of E-PrM 1 cysts housing only PCNA-positive spermatogonia was significantly
$(P<0.001)$ nearly sixfold greater than that of cysts housing both types of PCNA-positive testicular cells and cysts with PCNA-positive Sertoli cells only (Fig. 6B). Moreover the proportion of E-PrM 1 cysts containing PCNA-positive spermatogonia was significantly $(P<0.001)$ nearly threefold greater in the group of testes with the vacuolated type than for the MNC type of degeneration (Fig. 6B). Overall differences in PCNA immunostaining among E-PrM 2 cysts (Fig. 6C) were significant $(P<0.0001)$. In both types of degeneration the proportion of E-PrM 2 cysts housing only PCNApositive spermatogonia was significantly $(P<0.001)$ 5 - and 7.7-fold greater respectively than that of cysts housing both types of PCNA-positive testicular cells and cysts with PCNA-positive Sertoli cells only, in their respective categories of degeneration (Fig. 6C). The proportion of E-PrM 2 cysts containing PCNA-positive spermatogonia was significantly $(P<0.05) 1.5$-fold greater in the vacuolated type than in the MNC type of testes (Fig. 6C). Overall differences in PCNA 

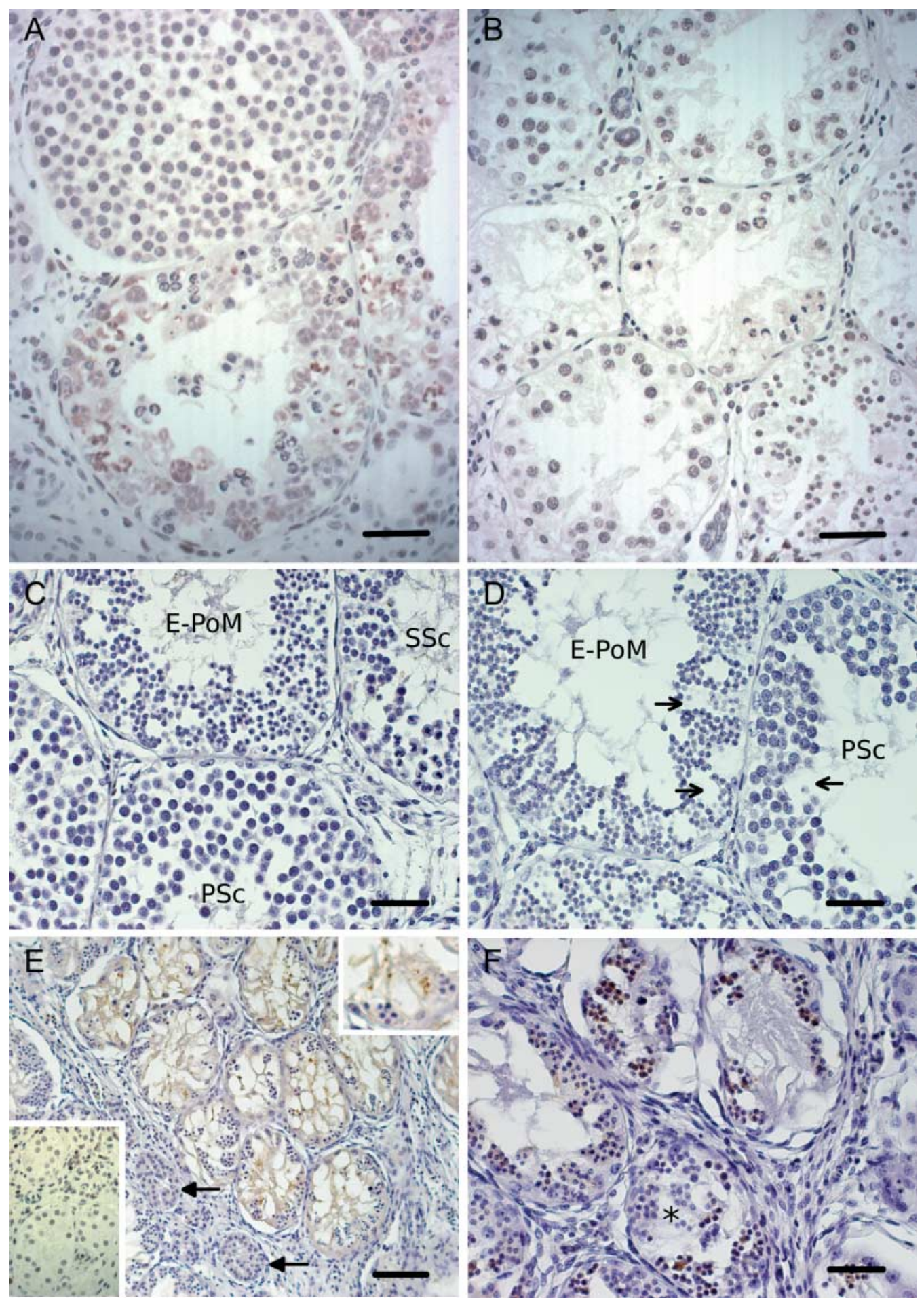

Figure 5 Comparison of (A and B) PCNA, (C and E) TUNEL and (D and F) cleaved caspase-3 immunostaining patterns of the various states of the mitosismeiosis transition in testicular cross-sections of $P$. glauca. PCNA immunostaining shows extensive MNC formation in spermatocyte cysts (A), from which some seem to recover giving rise to subnormal-sized cysts (B) containing spermatocytes showing nuclear PCNA immunoexpression. Normallooking (C and D), primary (PSc) and secondary (SSc) spermatocyte and round spermatid (E-PoM) cysts lack both TUNEL (A) and caspase-3 (B) labelling, despite some vacuolated areas (open arrows) due to germ cell loss. Note the paucity of cells in the interstitial compartment. In contrast as the period of $\mathrm{MNC}$ formation draws to a close, the last remaining germ cell corpses in the Sertoli cytoplasm are still detected by the TUNEL staining ( $E$, top inset, high magnification), while leftover normal-looking round spermatids in such cysts are caspase-3-labelled (F) and others are not (asterisk). Note the infiltration of epigonal organ-derived lymphoid cell aggregates (filled arrows) in the latter testicular conditions. (Bottom inset E) Lymphoid cell aggregates commonly seen in the epigonal organ are shown for comparative purposes. Scale bars: A, B, C, D and F=50 $\mu \mathrm{m} ; \mathrm{E}=100 \mu \mathrm{m}$. 
immunoreactivity among M-PrM, late (L)-PrM and spermatocyte cysts (Fig. 6D) were significant $(P=0.0197)$. Unlike in the group of sharks with MNC type of degeneration the proportion of M-PrM cysts housing PCNA-positive spermatogonia in the vacuolated

A

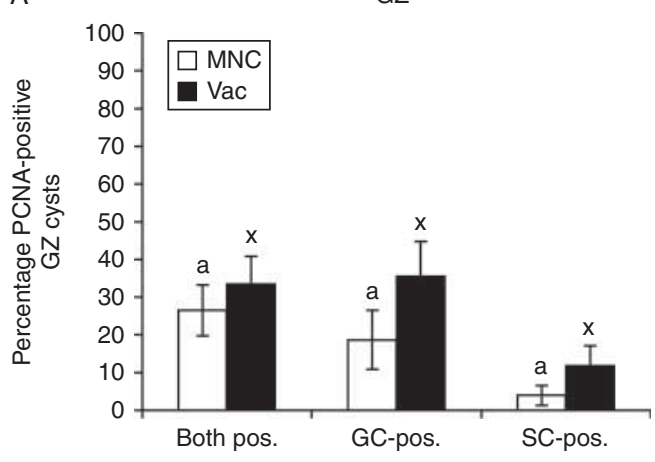

B

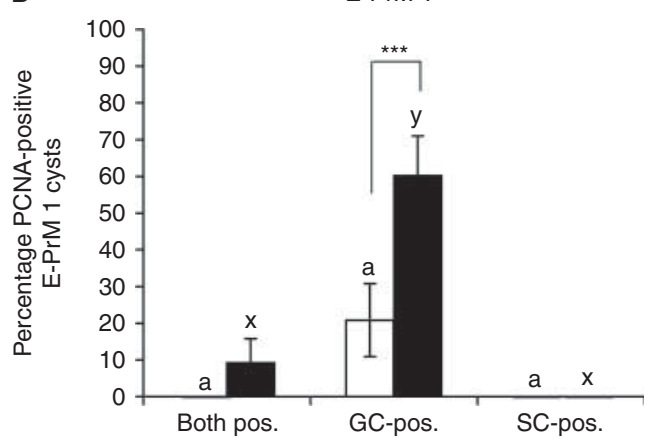

C

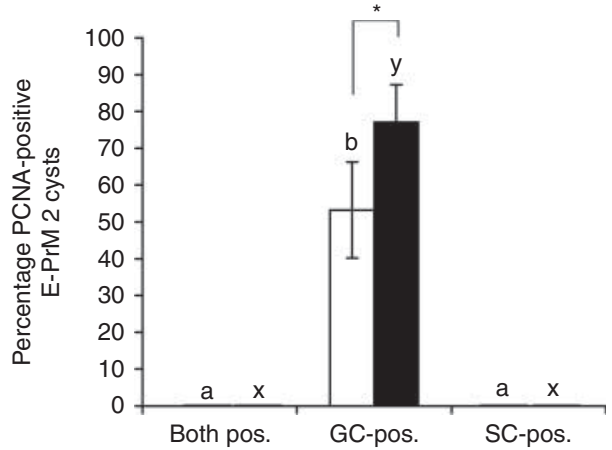

D

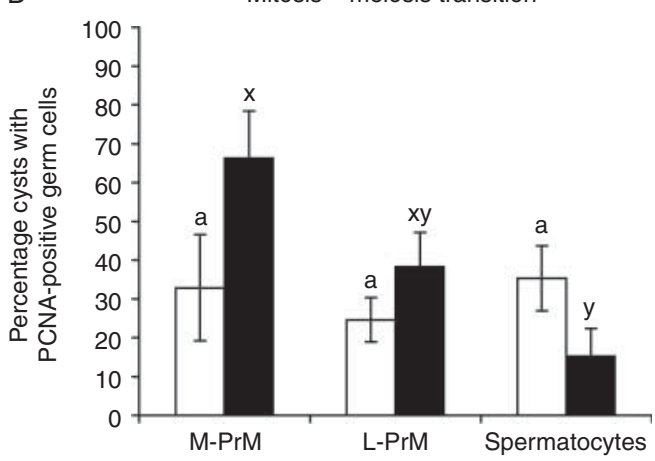

type of degeneration was significantly $(P<0.01) 4$.4-fold greater than that of PCNA-positive spermatocyte cysts (Fig. 6D).

Discordant labelling between TUNEL and cleaved caspase-3 immunohistochemistry characterised the rest of the PoM region that showed substantial cyst degeneration in a stage-related and cell-type-specific manner. A distinctive feature of PoM cysts housing disorderly arranged spermatids was the near absence of a cyst lumen and associated cytoplasmic TUNEL-labelling in hypertrophied Sertoli cells (Fig. 7A). However no such labelling of the hypertrophied Sertoli cells was observed in these degenerated PoM cysts when they were nearly depleted of germ cells (Fig. 7A). In comparison with cleaved caspase-3 immunohistochemistry the corresponding disorganised cysts showed only faint, diffuse caspase-3 labelling associated with the germ cell cytoplasm (Fig. 7B). Even when these degenerating PoM cysts were nearly depleted of germ cells the last remaining pockets of diffuse caspase- 3 labelling identified the last remaining few germ cells in these cysts (Fig. 7B). At a later stage of PoM cyst degeneration the TUNEL-negative Sertoli cytoplasm in these large Sertoli cell-only cysts became less dense a development that was associated with distinct TUNEL labelling (Fig. 7C), but no corresponding caspase-3 labelling (Fig. 7D) of their peripherally located Sertoli nuclei.

At this stage these strictly Sertoli cell-only degenerating PoM cysts were thoroughly embedded in the lymphomyeloid tissue of the epigonal organ and what followed next was the resorption of these Sertoli-cellonly cysts in the epigonal organ (Fig. 8). The resorption process was marked by the separation of one or two intensely basophilic nuclear components from the rest of the Sertoli nucleoplasm that was still strongly TUNELlabelled (Fig. 8A) but not caspase-3-labelled (Fig. 8B). This discordant immunolabelling between the TUNEL and cleaved caspase-3 approaches persisted even during advanced stages of cyst resorption in the epigonal organ during which the remnants of the Sertoli nucleoplasm were still visible as revealed by the mottled TUNEL staining (Fig. 8A). In contrast at an advanced stage of cyst resorption, the entire Sertoli cytoplasm of the resorbed cyst was distinctly caspase-3-immunolabelled with the intensely basophilic Sertoli nuclear components the only

Figure 6 Stage- and testicular cell type-related changes in the percentage of PCNA immunoreactive cysts in (A) GZ, (B) E-PrM 1, (C) EPrM 2 and (D) M-PrM, L-PrM and spermatocyte cysts in the two categories of testicular degeneration seen in Prionace glauca. Values represent the mean percentage of cysts \pm S.E.M. analyzed by one-way ANOVA. The Student-Newman-Keuls multiple comparisons test was used to identify means that differed significantly. Different letters indicate significant differences $(\mathrm{A}, \mathrm{B}$ and $\mathrm{C}, P<0.001 ; \mathrm{D}, P<0.01)$ in PCNA immunoreactivity in the MNC ( $a$ and $b$ ) and vacuolated ( $x$ and $y$ ) types of testicular degeneration. Differences between the two types of degeneration in a given category of PCNA immunoreactivity are significant $\left({ }^{*} P<0.05\right.$ and $\left.{ }^{* * *} P<0.001\right)$. 

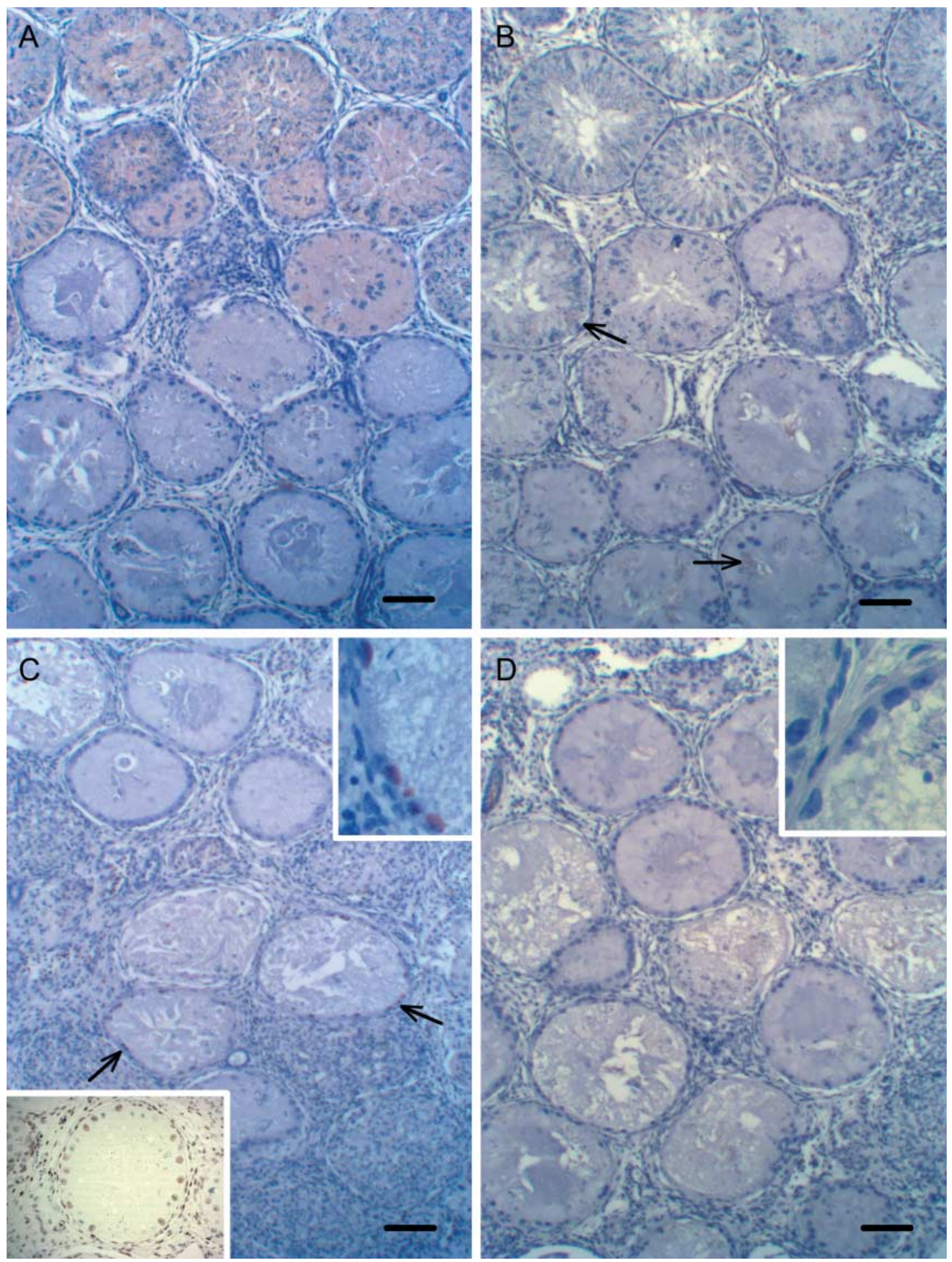

Figure 7 Immunostaining patterns of postmeiotic cyst degeneration in testicular cross-sections of $P$. glauca as revealed by (A and C) TUNEL and (B and D) cleaved caspase-3 and (bottom inset C) PCNA immunohistochemistry. When disorganised spermatid cysts still house germ cells that are in a disorderly arrangement (A, top half), the Sertoli cytoplasm in such cysts is TUNEL-labelled but labelling is absent when the cysts are nearly germ-celldepleted (A, bottom half). Corresponding cleaved caspase-3 immunohistochemistry shows germ cells in a disorderly arrangement in disorganised spermatid cysts (B, top half) with weak, diffuse cytoplasmic caspase-3 immunostaining (arrows), some of which is still associated with the last few remaining germ cells (B, arrows, bottom half) in nearly germ cell-depleted degenerated cysts. Before their resorption in the epigonal organ, the cytoplasm of the remaining hypertrophied Sertoli cells become less dense, a development associated with intense TUNEL staining of the Sertoli nuclei (C). (Top inset C) High magnification of area indicated by the arrow. (Bottom inset C) PCNA immunostaining of the corresponding cyst stage showing the PCNA-labelled Sertoli nuclei. The corresponding cyst stages completely lack caspase-3-immunoreactivity in all respects (D). (Inset D) High magnification showing caspase-3-negative Sertoli nuclei. Scale bar $=100 \mu \mathrm{m}$. 

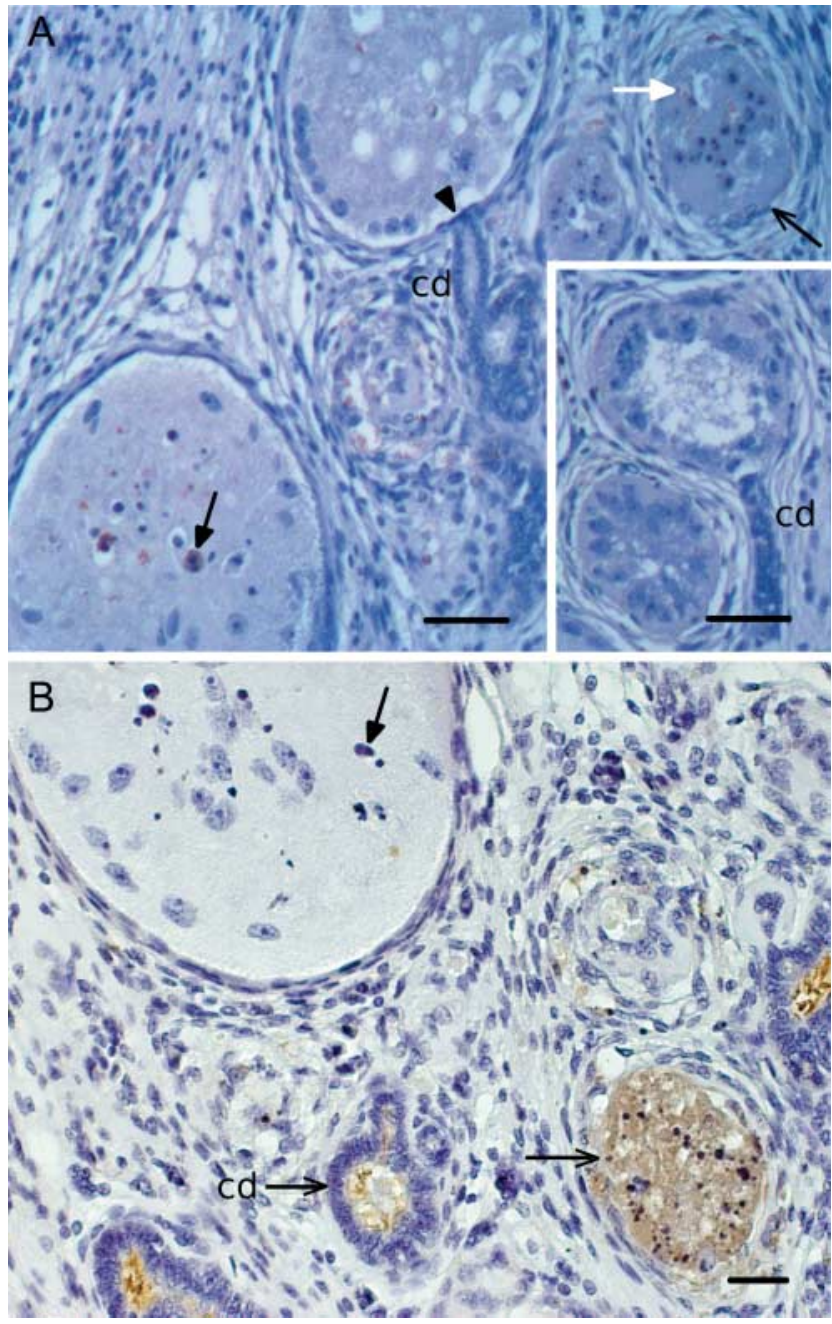

Figure 8 Immunostaining patterns of degenerated Sertoli cell-only PoM cysts undergoing resorption in the epigonal organ in testicular crosssections of $P$. glauca as revealed by (A) TUNEL and (B) cleaved caspase3 immunohistochemistry. The nuclear compartment of the TUNELlabelled Sertoli nucleus separates into two parts, i.e. one or two intensely basophilic components with the rest of the nuclear matrix still intensely TUNEL-labelled (A, filled black arrow) but not caspase-3 labelled (B, filled black arrow). With the resorption process well underway mottled TUNEL staining (A, filled white arrow) indicates the remains of dismantled Sertoli nuclei. In comparison only the Sertoli cytoplasm is strongly caspase- 3 immunostained (B, open arrow). (Inset A) The TUNEL-negative evacuated cyst with its well-defined cyst lumen and patent collecting duct (cd) that connects in a funnel-like manner to the cyst. Note the corresponding site in a degenerated PoM cyst showing a structural modification at the base of the Sertoli cell (arrowhead). Scale bars: $A=50 \mu \mathrm{m}$ and $B=30 \mu \mathrm{m}$.

remaining evidence of the dismantled Sertoli nuclei (Fig. 8B). As positive controls, TUNEL and cleaved caspase-3 immunohistochemistry of testicular crosssections of thresher shark (Alopias vulpinus) caught together with these blue shark at the same fishing tournament showed none of the phenomena described earlier and immunohistochemical labelling patterns differed both qualitatively and quantitatively from that seen in $P$. glauca (not shown).

\section{Discussion}

Unlike in Scyliorhinus canicula (Dobson \& Dodd 1977) and Squalus acanthias (McClusky 2005), spermatogenesis in summer mating blue sharks also entails massive germ cell apoptosis in meiotic and PoM cysts. This study further reports on another variation of the spatially graded pattern of testicular cell death in elasmobranchs but which differs in quality and quantity from that seen in other shark species namely stage-related differences in the manner the elimination phase of apoptosis proceeds. It was found that whereas apoptotic coalesced type B spermatogonia in M-PrM and L-PrM cysts and spermatocytes were phagocytised deep within the germinal epithelium apoptotic coalesced type B spermatogonia in E-PrM cysts were fragmented into numerous small apoptotic bodies which were subsequently displaced in the direction of the perilumenar Sertoli nuclei. Apoptotic bodies or other cell debris were never found in the cyst lumen itself. Evidence presented here also suggests that the adoption of a concave shape by perilumenar Sertoli nuclei may be to partially envelop around the apoptotic bodies, supposedly to expedite their elimination. The latter is also a well-known phenomenon in the testis of another shark (McClusky 2005) and other lower vertebrates (Yazawa et al. 2000, Sasso-Cerri et al. 2006).

Testicular apoptosis reported here for Prionace glauca displays mixed features of cellular death and is in many ways yet another example of the different morphologies of physiological cell death known to occur in vivo in various tissues (Roach \& Clarke 2000, Kroemer et al. 2008). On the whole however the sequence of events in spermatogonial death in E-PrM cysts in Prionace resembles that which has been referred to as the secondary necrosis phase seen in some forms of apoptosis (Kroemer et al. 2008, Silva et al. 2008). Secondary necrosis is understood to be a form of selfelimination that occurs when removal by a phagocyte does not occur (Silva et al. 2008). As the debris of dead E-PrM cyst spermatogonia are eventually removed, it is therefore postulated that these immature E-PrM Sertoli cells are probably incapable of promptly phagocytising dead germ cells. It is worth noting that a subpopulation of degenerating germ cells in the fetal mouse testis with its immature Sertoli cells has also been described as necrotic (Wang et al. 1998), and by implication somewhat more persisting than apoptotic germ cells that are immediately phagocytosed (Roach \& Clarke 2000). Alternatively, the persisting cell corpses in the testis of $P$. glauca may suggest the lack of the appropriate surface recognition molecules generally on the elasmobranch Sertoli cell and/or apoptotic bodies that are needed to effectuate prompt phagocytosis (Rovere-Querini \& Dumitriu 2003). Mammalian testes 
either lacking the ELMO1 cytoplasmic engulfment protein in germ cells (Elliott et al. 2010) or housing only immature (Morton et al. 1986) or worn-out Sertoli cells (e.g. as in the aged human testis; Paniagua et al. 1987, Miething 1993) feature reduced clearance of dying germ cells and a preponderance of large numbers of multinucleate germ cells. By extension then the predominant expression of testicular apoptosis in $P$. glauca as MNC formation may likewise be a reflection of inadequate mechanisms in Sertoli cells to clear apoptotic germ cell masses promptly. Similar unconventional morphologies of cell death involving the simultaneous death of large numbers of cells in the testis (Bartke 1995) and other tissues may, as suggested by (Roach \& Clarke 2000), be explained as overloaded phagocytic responses and the activation of tissuespecific mechanisms that, in some cases, may even resemble necrotic death.

Established dogma informs that a cell has to be in the cell cycle for it to be diverted towards the apoptotic death pathway. Unexpected findings in this study were the intense overall PCNA-labelling that was distinctly different from the homogeneous labelling seen in cycling spermatogonial and Sertoli nuclei and which immunodetected single apoptotic and multinucleate spermatogonial masses in spermatogonial cysts. These observations were similar to the intense PCNA immunostaining of apoptotic cells seen in the regressing rat ventral prostate (Colombel et al. 1992), mouse cerebellum (Migheli et al. 1997) and cultured bovine embryos (Makarevich \& Markkula 2002). A possible explanation for the co-immunoexpression of PCNA in apoptotic spermatogonia could be that the apoptotic programme is switched on while these cells are engaged in their protracted cell cycle and/or the initiation of DNA repair mechanisms that involve the participation of PCNA (Maga \& Hubscher 2003). The expected complete absence of PCNA immunoreactivity in large coalesced cytoplasmic masses of dead spermatogonia further supports these notions.

Nowhere among the vertebrates is the morphological association between the reproductive and immune systems so pronounced as in cartilaginous fishes. These findings show the role played by the epigonal organ in the removal of degenerated PoM cysts in the postspermiation phase of the blue shark. Preceding events included the activation of caspase-3-dependent Sertoli cell apoptosis in those PoM cysts in which the post-MNC recovery of cysts with an abnormally low Sertoli:germ cell ratio eventually aborted. These degenerated and unwanted cysts were resorbed in the lymphomyeloid tissue mass of the epigonal organ. Interestingly, the postspawning phase of male gilthead sea bream also featured leukocyte infiltration concomitant with spermatogonial apoptosis and phagocytosis of the remaining spermatozoa by Sertoli cells, and which were found to be part of the recovery process in this teleost (Besseau \& Faliex 1994).

The size of the epigonal organ and the extent of gonad-epigonal organ contact varies among different shark species (Honma et al. 1984). Lymphomyeloid cell infiltration as described here in Prionace was never observed in Squalus acanthias (L M McClusky, unpublished observations), all of which could possibly relate to the extensive PoM cyst degeneration seen in Prionace and not in Squalus. It can be speculated whether this uniquely positioned lymphomyeloid tissue mass may in effect represent an evolutionary ancient redundant/fail-safe mechanism for the phagocytosis duties of still successively maturing, temporary elasmobranch Sertoli cells. It is possible that the commencement of Sertoli cell phagocytosis of the highly antigenic spermatids may be the trigger of a prompt epigonal organ response during which the Sertoli cells themselves are engulfed and eliminated by the infiltrating lymphomyeloid cell aggregates. Furthermore the curious finding in $P$. glauca but not in Squalus acanthias regardless of spermatogenic state (L M McClusky, unpublished observations) of only the white stromal-rich germinal ridge, which houses the germinal and supporting somatic stem cells, extending along the surface of the epigonal organ, is further evidence of species differences with regards to the extent of gonad-epigonal organ interaction in elasmobranchs (Honma et al. 1984).

The severe degenerative phenomena described here in the blue shark are not injuries or artificially induced because other recreationally fished elasmobranchs with similar testis type and necropsied even up to $8 \mathrm{~h}$ after landing, e.g. Galeorhinus galeus (McClusky 2003), as well as other species with the compound testis type (Alopias vulpinus, this study) which were caught and handled under the same conditions, do not show any of these phenomena. This indicates that these degenerative phenomena as described here for $P$. glauca are biologically significant.

Given the protracted nature of spermatogenesis described for another northwest Atlantic shark, Squalus acanthias (McClusky 2005), an overall synthesis therefore of degenerative events in $P$. glauca may be as illustrated in Fig. 9. Initial massive MNC formation affecting predominantly the late-stage type B spermatogonia in M-PrM and L-PrM cysts and spermatocyte cysts in the blue shark leaves its imprint in the spermatogenic sequence in the form of vacuolated areas in the affected and subsequent cyst stages. The vacuolated type of testicular morphology therefore represents in essence the recovery phase from the earlier pronounced MNC death. Findings in this study of a higher PCNA index of spermatogonia in the vacuolated compared to the multinucleate type of degeneration are consistent with this reasoning. With new cysts entering the spermatogenic sequence at the GZ the aftermath of degeneration at the mitosis-meiosis transition, i.e. the vacuolated 


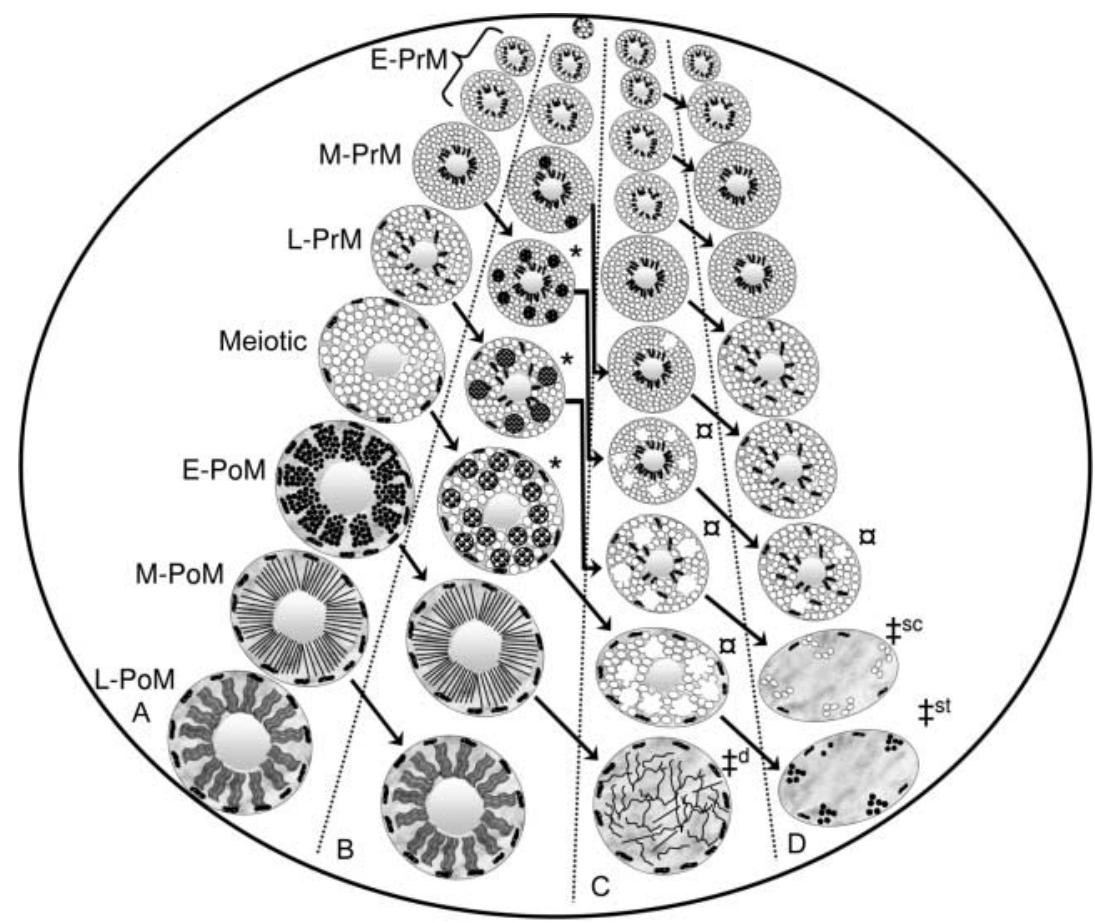

Figure 9 Cross-sectional schematic representation of the major spatiotemporal changes (indicated by columns A, B, C and D) in the testis of Prionace glauca. Any given testicular cross-section is a snapshot of the spermatogenic sequence at a given point in time and which facilitates extrapolation of spermatogenic development backwards and forward in time. GZ cysts are omitted for the sake of space. All cyst stages are present, though in varying proportions, in a cross-section of a sexually mature male before the onset of degeneration (A), which sets in as a graded incidence of multinucleate cell formation in specific PrM cyst stages (*, B). The vacuolated appearance in mainly the PrM cysts containing the later type B spermatogonia and spermatocyte cyst stages (general currency sign) is the outcome of the phagocytic removal of the multinucleate germ cell corpses by associated Sertoli cells (C). An elevated PCNA index in E-PrM and M-PrM cysts and subsequent increased cyst numbers in the PrM region are all indicative testicular recovery/recrudescence. This and the gradual cessation of degenerative processes result in the formation of a distinct ZD especially in cysts at the mitosis-meiosis transition (general currency sign, C). Some remaining germ cells may recover though but these flattened meiotic $\left(\ddagger^{\mathrm{sc}}\right)$ and $\mathrm{E}-\mathrm{PoM}\left(\neq^{\mathrm{st}}\right)$ cysts eventually also abort, at which time the testis has a near full complement of normal PrM cysts (D).

state, will only manifest in the PoM region when the testis is recovering. As shown in the previous study (McClusky 2011) MNC formation affects some cysts more than others, but the remaining germ cells in an affected clone seem to recover and progress to the next stage until further development is aborted and they eventually are phagocytised. Why cyst recovery does not proceed to the mature spermatid stage is not certain. The Sertoli:germ cell ratio in these cysts could be a determining factor with further cyst development aborted if the ratio is suboptimal.

Sertoli cells undergo hypertrophy and phagocytose the remaining degenerating spermatids, which may explain the TUNEL-positive Sertoli cytoplasm. However diffuse cleaved caspase-3-immunolabelling of leftover but supposedly recovering germ cells in subnormal-sized and disorganised cysts indicates that the apoptotic death programme is activated in these germ cells. Cysts take on a distinctive Sertoli-cell-only character after all the spermatids have been phagocytised, all of which is associated with the loss of both TUNEL- and cleaved caspase-3-immunoreactivity. It was previously thought, based on histological observations, that these degenerating Sertoli-cell-only PoM cysts were transformed evacuated cysts (McClusky 2011), an interpretation that now needs to be revised in the light of these immunohistochemical observations. The observed appearance of cleaved caspase-3-immunoreactivity in the cytoplasm of Sertoli-cell-only PoM cysts undergoing resorption in the epigonal organ agrees in principle with the discovered role of a caspase-3-like protease in the removal of bulk cytoplasm in a non-apoptotic event during insect spermatogenesis (Arama et al. 2003).

In conclusion findings presented here show that the spatial expression of testicular apoptosis in some carcharhinid sharks is most likely species-specific and appears not to be related to the particular testicular organisation such species might share.

\section{Materials and Methods}

\section{Animals}

P. glauca is a highly migratory, pelagic shark species with a circumglobal distribution in temperate and tropical waters. Their movement patterns exhibit a spatial structure related to reproduction and distribution of prey. Their complex 
reproductive cycle includes the congregation of individuals on the continental shelf off southern New England (USA) during the summer months for purposes of mating (Pratt 1979) followed by their departure off the shelf in October towards warmer waters. Consequently year-round investigations of the reproductive biology of this near-threatened species are problematic and the few opportunities that facilitate access to the tissues of this species should be fully utilised. The animals used in this study are the same ones as those of an earlier report (McClusky 2011). Briefly, 19 adult males (67.3-120 kg; 213$262 \mathrm{~cm}$ fork-length), many with their hearts still beating, were landed by recreational fisherman participating in sports-fishing tournaments held in the period May-July 2007 in Montauk Point (New York) and Martha's Vineyard (Massachusetts) along the southern New England coast of the USA. All subsequent animal handling and dissections were conducted under the auspices of attending fisheries scientists from the National Oceanic and Atmospheric Administration Fisheries Service, Narragansett, Rhode Island.

\section{Tissue preparation}

Testes were dissected out and much of the attached epigonal organ tissue (Fig. 10) was cut away. Representative crosssections (3-5 mm) were cut midway along the length of both testes and fixed in $10 \%$ buffered elasmobranch formalin (Prieur et al. 1976) for 24 h. Fixed tissues were stored in $70 \%$ ethanol until further processing. Tissues were embedded in paraffin wax and processed for routine histological analysis by way of haematoxylin and eosin staining and immunohistochemistry.

\section{TUNEL immunohistochemistry}

Procedures previously optimised for shark testicular tissues were followed (McClusky 2005). Briefly paraffin sections (4-5 $\mu \mathrm{m}$ thick) were cut and collected onto superfrost plus glass slides deparaffinised and rehydrated stepwise through an ethanol series. Sections were treated with $0.1 \%$ $(\mathrm{v} / \mathrm{v})$ Triton $\mathrm{X}-100$ in $0.1 \%(\mathrm{w} / \mathrm{v})$ sodium citrate for $2 \mathrm{~min}$ at

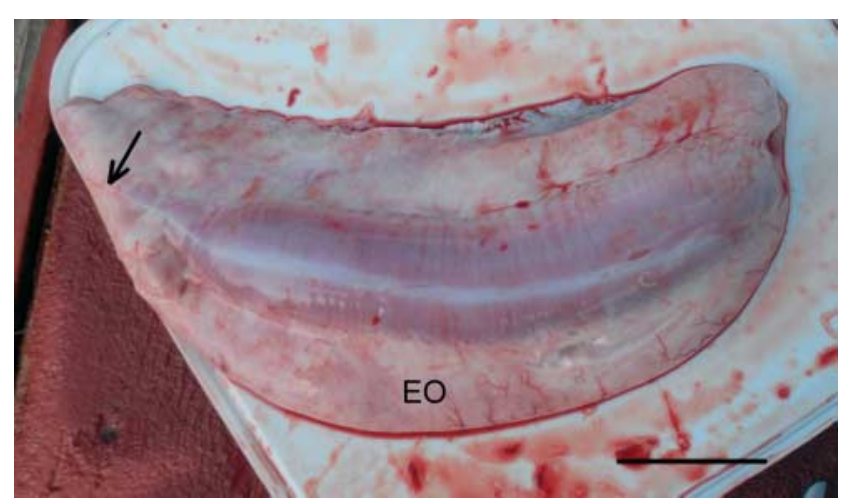

Figure 10 Ventral view of the testis of the adult male blue shark. Spermatocysts originate in the white, fibrous germinal ridge on the ventral side of the testis, and which can also extend separately (arrow) along the surface of the epigonal organ (EO). Scale bar $=4 \mathrm{~cm}$. room temperature (RT), followed by two rinses in PBS $(50 \mathrm{mM}$ sodium phosphate, $\mathrm{pH} 7.4$, and $200 \mathrm{mM} \mathrm{NaCl}$, referred to here as PBS-A). Endogenous peroxidase was quenched by treating sections in darkness with $3 \%(\mathrm{v} / \mathrm{v})$ hydrogen peroxide for 10 min followed by two washes in PBS-A. Subsequent steps for TUNEL staining were taken as per supplier's instructions of the ApopTag-Peroxidase kit (Merck Millipore, Billerica, MA, USA), except that the terminal transferase enzyme (TdT) was diluted $1: 16$ with sterile water. Following incubation of the sections with the TUNEL reaction mixture in humidified chamber at $37{ }^{\circ} \mathrm{C}$ for $1 \mathrm{~h}$, anti-digoxigenin-peroxidase complex was added for $30 \mathrm{~min}$ at RT. Sections were then treated with a 3,3'-diaminobenzidine (DAB) kit for 1-2 min according to the supplier's instructions (Vector Laboratories, Burlingame, CA, USA) after which positive cells stained brown. Sections were counterstained for $45 \mathrm{~s}$ with Hematoxylin QS (Modified Mayer's Formula; Vector Laboratories), rinsed in running tap water for $5 \mathrm{~min}$, dehydrated three times (45 s each) in 100\% butanol, cleared in xylene and mounted with Entellan (Merck). For comparison and as positive controls, testicular sections from the thresher shark ( $A$. vulpinus) caught at the same time and catfish (Clarias gariepinus) (McClusky et al. 2008) were processed simultaneously.

\section{Cleaved caspase-3 immunohistochemistry}

Procedures previously optimised for fish testicular tissues were followed (McClusky et al. 2008). Briefly paraffin sections (4-5 $\mu \mathrm{m}$ thick) were cut and collected onto superfrost plus glass slides, deparaffinised and rehydrated stepwise through an ethanol series. Sections were subjected to an antigen retrieval procedure by heating the sections in a microwave oven $(800 \mathrm{~W})$ in $10 \mathrm{mM}$ sodium citrate buffer $(\mathrm{pH}$ 6.0) for $10 \mathrm{~min}$. After cooling for $20 \mathrm{~min}$ at RT endogenous peroxidase was quenched by treating sections in darkness with $3 \%(\mathrm{v} / \mathrm{v})$ hydrogen peroxide for $10 \mathrm{~min}$. Following a rinse in distilled water the sections were placed in $0.1 \%$ Tween 20 in PBS (137 $\mathrm{mM} \mathrm{NaCl}, 29 \mathrm{mM} \mathrm{NaH} \mathrm{PO}_{4} \cdot \mathrm{H}_{2} \mathrm{O}$, and $9 \mathrm{mM} \mathrm{Na}{ }_{2} \mathrm{HPO}_{4}$, $\mathrm{pH} 7.4$, referred to hereafter as PBS-B) for $5 \mathrm{~min}$. Sections were then incubated for $1 \mathrm{~h}$ at RT with blocking solution (5\% normal goat serum in $0.1 \%$ Tween 20-PBS-B) to reduce non-specific binding and then overnight at $4{ }^{\circ} \mathrm{C}$ with a rabbit polyclonal antibody to cleaved caspase-3 (17/19 kDa fragment of activated caspase-3; Cell Signaling Technology, Beverly, MA, USA) diluted 1:400 in blocking solution. After three washes in $0.1 \%$ Tween 20-PBS-B sections were incubated with biotinylated anti-rabbit IgG for $30 \mathrm{~min}$ at RT washed in PBS-B and then incubated with the Vectastain avidin-biotin complex (Vector Laboratories) for a further $30 \mathrm{~min}$ at RT. Following three 5-min PBS-B washes the antigen was finally detected by treating the sections with the DAB kit for 1-2 min, counterstained, dehydrated, cleared and mounted as described in the previous section for TUNEL immunohistochemistry. Negative controls were generated by omitting the primary antibody and by serial dilution of the primary antibody. For positive controls, testicular sections from the thresher shark (A. vulpinus) caught at the same time and catfish, $C$. gariepinus (McClusky et al. 2008), were processed simultaneously. 


\section{PCNA immunohistochemistry}

Procedures were performed as described previously (Borucinska et al. 2008). Briefly, paraffin sections (4-5 $\mu \mathrm{m}$ thick) were cut and collected onto silane-coated glass slides, deparaffinised and rehydrated stepwise through an ethanol series. After quenching endogenous peroxidase activity with freshly prepared $3 \%$ hydrogen peroxide, sections were subjected to an antigen retrieval procedure, which entailed incubating sections for $10 \mathrm{~min}$ in 'Retrieve-all' $\mathrm{pH} 8.0$ (Signet Laboratories, Dedham, MA, USA) in a steamer bath, followed by 10-min 'cool down' at RT. After two washes in diluted Cadenza buffer wash (Thermo Electron Corp., Waltham, MA, USA) which was also used in all subsequent washes, sections were then incubated with Omnitags protein blocking solution (Thermo Electron Corp.) for 5-10 $\mathrm{min}$ at RT to reduce non-specific binding and then overnight at RT with anti-PCNA PC10 (a mouse MAB derived against a recombinant mouse PCNA consisting of amino acids 112-121; Calbiochem, San Diego, CA, USA) at final concentration $0.001 \mu \mathrm{g} / \mu \mathrm{l}$. After three buffer washes, sections were incubated at 1:40 dilution in biotinylated anti-mouse secondary antibody (Thermo Electron Corp.) for $30 \mathrm{~min}$ at RT followed by incubation with the Vectastain streptavidin-peroxidase complex (Vector Laboratories) for a further $20 \mathrm{~min}$ at RT. Following three 5-min washes, the antigen was finally detected by treating the sections with Vector Nova Red substrate kit (Vector Laboratories) for $10 \mathrm{~min}$, counterstained with Shandon Gill 2 haematoxylin (Thermo Electron Corp.), dehydrated, cleared and mounted with Permount (Fisher, Fairlawn, NJ, USA). Negative controls were generated by incubating sections with optimally diluted mouse isotype antibody (Thermo Electron Corp.).

\section{Microscopical analysis}

The diametric elasmobranch testis type provides a readily visible zonation, i.e. the $\operatorname{PrM}$, meiotic $(\mathrm{M})$ and the PoM regions. This testicular organisation also facilitates the microscopic study of substages within each major region. Thus, the PrM region comprises cysts in the GZ in which both Sertoli and types A and B spermatogonia have contact with the cyst basal lamina, and cysts with type B spermatogonia that are orderly arranged around the periphery in one, and two to three (early stage, E-PrM 1 and E-PrM 2 respectively), four to five (mid-stage, M-PrM) and five or more (late stage, L-PrM) layers. The $M$ region consists of cysts housing primary and secondary spermatocytes and the PoM region cysts with spermatids at the round (early stage, E-PoM), elongating (mid-stage, M-PoM) and mature (late-stage, L-PoM) stage.

Quantitative analysis of all the cyst stages seen in a testicular cross-section was performed as described previously (McClusky 2005, 2011). Briefly, all cysts along three lines radiating from the white, stromal-rich germinal ridge (Fig. 10) to the proximal border of the mature testis pole were counted and classified by stage and substage and type of degeneration noted. A cyst was classified as degenerated if it contained a minimum of three clusters of multinucleate giant cells or three large vacuolated spaces or if its cellular content was disorganised with or without the presence of abnormally developed nuclei. To quantify cell death phenomena among E-PrM cysts a cyst was grouped as apoptotic body-positive if it contained three or more clumps of perilumenar condensed chromatin. For PCNA scoring each cyst was scored separately for PCNA-labelled germ cells and/or Sertoli cells, and a cyst in which more than $\sim 50 \%$ of nuclei of a given cell type was PCNA stained was considered positive (cellular events proceed in a wave-like manner in any given cyst and germ cells in a cyst may not always be synchronised).

\section{Statistical analysis}

All raw percentage data were arcsine-square-root transformed before analysis by one-way ANOVA (see figure legends) using Instat version 2.03 (GraphPad Software, San Diego, CA, USA). Student-Newman-Keuls multiple comparisons test was used to determine which values differed significantly $(P<0.05)$.

\section{Declaration of interest}

The authors declare that there is no conflict of interest that could be perceived as prejudicing the impartiality of the research reported.

\section{Funding}

This study was made possible, in part, by funding from the Research Council of Norway.

\section{Acknowledgements}

The author is greatly indebted to Dr Joanna Borucinska, Department of Biology, University of Hartford, Connecticut, USA, for supplying the tissues and carrying out the PCNA immunohistochemistry.

\section{References}

Arama E, Agapite J \& Steller H 2003 Caspase activity and a specific cytochrome c are required for sperm differentiation in Drosophila. Developmental Cell 4 687-697. (doi:10.1016/S1534-5807(03)00120-5)

Bartke A 1995 Apoptosis of male germ cells, a generalized or a cell typespecific phenomenon? Endocrinology 1363-4. (doi:10.1210/en.136.1.3)

Besseau L \& Faliex E 1994 Resorption of unemitted gametes in Lithognathus mormyrus (Sparidae, Teleostei): a possible synergic action of somatic and immune cells. Cell and Tissue Research 276 123-132. (doi:10.1007/ BF00354791)

Billig H, Furuta I, Rivier C, Tapanainen J, Parvinen M \& Hsueh AJ 1995 Apoptosis in testis germ cells: developmental changes in gonadotropin dependence and localization to selective tubule stages. Endocrinology 136 5-12. (doi:10.1210/en.136.1.5)

Borucinska JD, Schmidt B, Tolisano J \& Woodward D 2008 Molecular markers of cancer in cartilaginous fish: immunocytochemical study of PCNA, p-53, myc and ras expression in neoplastic and hyperplastic tissues from free ranging blue sharks, Prionace glauca (L.). Journal of Fish Diseases 31 107-115. (doi:10.1111/j.1365-2761.2007.00871.x)

Colombel M, Olsson CA, Ng P-Y \& Buttyan R 1992 Hormone-regulated apoptosis results from reentry of differentiated prostate cells onto a defective cell cycle. Cancer Research 52 4313-4319.

Corriero A, Desantis S, Bridges CR, Kime DE, Megalofonou P, Santamaria N, Cirillo F, Ventriglia G, Di Summa A, Deflorio M et al. 
2007 Germ cell proliferation and apoptosis during different phases of swordfish (Xiphias gladius L.) spermatogenetic cycle. Journal of Fish Biology 70 83-99. (doi:10.1111/j.1095-8649.2006.01257.x)

Dobson S \& Dodd JM 1977 Endocrine control of the testis in the dogfish Scyliorhinus canicula L. II. Histological and ultrastructural changes in the testis after partial hypophysectomy (ventral lobectomy). General and Comparative Endocrinology 32 53-71. (doi:10.1016/0016-6480 (77) $90082-X)$

Dym M \& Fawcett DW 1971 Further observations on the numbers of spermatogonia, spermatocytes, and spermatids connected by intercellular bridges in the mammalian testis. Biology of Reproduction 4 $195-215$.

Elliott MR, Zheng S, Park D, Woodson RI, Reardon MA, Juncadella IJ, Kinchen JM, Zhang J, Lysiak JJ \& Ravichandran KS 2010 Unexpected requirement for ELMO1 in clearance of apoptotic germ cells in vivo. Nature 467 333-337. (doi:10.1038/nature09356)

Honma Y, Okabe K \& Chiba A 1984 Comparative histology of the Leydig and epigonal organs in some elasmobranchs. Japanese Journal of Ichthyology 318.

Kroemer G, Galluzzi L, Vandenabeele P, Abrams J, Alnemri ES, Baehrecke EH, Blagosklonny MV, El-Deiry WS, Golstein P, Green DR et al. 2008 Classification of cell death: recommendations of the Nomenclature Committee on Cell Death 2009. Cell Death and Differentiation 16 3-11. (doi:10.1038/cdd.2008.150)

Maga G \& Hubscher U 2003 Proliferating cell nuclear antigen (PCNA): a dancer with many partners. Journal of Cell Science 116 3051-3060. (doi:10.1242/jcs.00653)

Makarevich AV \& Markkula M 2002 Apoptosis and cell proliferation potential of bovine embryos stimulated with insulin-like growth factor I during in vitro maturation and culture. Biology of Reproduction 66 386-392. (doi:10.1095/biolreprod66.2.386)

McClusky LM 2003 A scanning electron microscopic study of germ cell maturation in the reproductive tract of the male soupfin shark (Galeorhinus galeus). Acta Zoologica 84 69-76. (doi:10.1046/j.1463-6395.2003.00132.x)

McClusky LM 2005 Stage and season effects on cell cycle and apoptotic activities of germ cells and Sertoli cells during spermatogenesis in the spiny dogfish (Squalus acanthias). Reproduction 129 89-102. (doi:10.1530/rep.1.00177)

McClusky LM 2006 Stage-dependency of apoptosis and the blood-testis barrier in the dogfish shark (Squalus acanthias): cadmium-induced changes as assessed by vital fluorescence techniques. Cell and Tissue Research 325 541-553. (doi:10.1007/s00441-006-0184-6)

McClusky LM 2011 Testicular degeneration during spermatogenesis in the blue shark, Prionace glauca: nonconformity with expression as seen in the diametric testes of other carcharhinids. Journal of Morphology $\mathbf{2 7 2}$ 938-948. (doi:10.1002/jmor.10958)

McClusky LM, Barnhoorn IE, van Dyk JC \& Bornman MS 2008 Testicular apoptosis in feral Clarias gariepinus using TUNEL and cleaved caspase-3 immunohistochemistry. Ecotoxicology and Environmental Safety 71 41-46. (doi:10.1016/j.ecoenv.2008.03.017)

Miething A 1993 Multinucleated spermatocytes in the aging human testis: formation, morphology, and degenerative fate. Andrologia 25 317-323. (doi:10.1111/j.1439-0272.1993.tb02733.x)

Migheli A, Piva R, Wei J, Attanasio A, Casolino S, Hodes ME, Dlouhy SR, Bayer SA \& Ghetti B 1997 Diverse cell death pathways result from a single missense mutation in weaver mouse. American Journal of Pathology 151 1629-1638.
Morton D, Weisbrode SE, Wyder WE, Maurer JK \& Capen CC 1986 Spermatid giant cells, tubular hypospermatogenesis, spermatogonial swelling, cytoplasmic vacuoles, and tubular dilatation in the testes of normal rabbits. Veterinary Pathology 23 176-183. (doi:10.1177/ 030098588602300211)

Paniagua R, Nistal M, Amat P, Rodriguez MC \& Martin A 1987 Seminiferous tubule involution in elderly men. Biology of Reproduction 36 939-947. (doi:10.1095/biolreprod36.4.939)

Pratt HL 1979 Reproduction in the blue shark, Prionace glauca. Fishery Bulletin 77 445-470.

Prieur DJ, Fenstermacher JD \& Guarino AM 1976 A choroid plexus papilloma in an elasmobranch (Squalus acanthias). Journal of the National Cancer Institute 56 1207-1209.

Pudney J 1995 Spermatogenesis in nonmammalian vertebrates. Microscopy Research and Technique 32 459-497. (doi:10.1002/jemt.1070320602)

Roach HI \& Clarke NM 2000 Physiological cell death of chondrocytes in vivo is not confined to apoptosis. New observations on the mammalian growth plate. Journal of Bone and Joint Surgery. British Volume 82 601-613. (doi:10.1302/0301-620X.82B4.9846)

Rovere-Querini P \& Dumitriu IE 2003 Corpse disposal after apoptosis. Apoptosis 8 469-479. (doi:10.1023/A:1025538324077)

Russell LD \& Clermont Y 1977 Degeneration of germ cells in normal, hypophysectomized and hormone treated hypophysectomized rats. Anatomical Record 187 347-366. (doi:10.1002/ar.1091870307)

Sasso-Cerri E, Cerri PS, Freymuller E \& Miraglia SM 2006 Apoptosis during the seasonal spermatogenic cycle of Rana catesbeiana. Journal of Anatomy 209 21-29. (doi:10.1111/j.1469-7580.2006.00582.x)

Schulz RW, Menting S, Bogerd J, Franca LR, Vilela DA \& Godinho HP 2005 Sertoli cell proliferation in the adult testis - evidence from two fish species belonging to different orders. Biology of Reproduction $\mathbf{7 3}$ 891-898. (doi:10.1095/biolreprod.105.039891)

Silva M, do Vale A \& dos Santos N 2008 Secondary necrosis in multicellular animals: an outcome of apoptosis with pathogenic implications. Apoptosis 13 463-482. (doi:10.1007/s10495-008-0187-8)

Wang RA, Nakane PK \& Koji T 1998 Autonomous cell death of mouse male germ cells during fetal and postnatal period. Biology of Reproduction $\mathbf{5 8}$ 1250-1256. (doi:10.1095/biolreprod58.5.1250)

Yazawa T, Yamamoto T \& Abe S 2000 Prolactin induces apoptosis in the penultimate spermatogonial stage of the testes in Japanese redbellied newt (Cynops pyrrhogaster). Endocrinology 141 2027-2032. (doi:10.1210/en.141.6.2027)

Yazawa T, Nakayama Y, Fujimoto K, Matsuda Y, Abe K, Kitano T, Abe S \& Yamamoto T 2003 Abnormal spermatogenesis at low temperatures in the Japanese red-bellied newt, Cynops pyrrhogaster: possible biological significance of the cessation of spermatocytogenesis. Molecular Reproduction and Development 66 60-66. (doi:10.1002/ mrd.10328)

Received 8 June 2012

First decision 6 August 2012

Revised manuscript received 10 January 2013

Accepted 15 January 2013 